\title{
Modelling the Impact of Conformal Coating Penetration on QFN Reliability
}

\author{
Chunyan Yin, Stoyan Stoyanov, Chris Bailey \\ Department of Mathematical Sciences \\ University of Greenwich \\ London, UK. SE10 9LS \\ c.yin@gre.ac.uk
}

\author{
Paul Stewart \\ Leonardo MW Ltd \\ Edinburgh, UK. EH5 2XS \\ paul.stewart02@leonardocompany.com
}

\begin{abstract}
The impact of conformal coating penetration on the solder joints' thermal fatigue reliability in QFNs was studied using computational modeling techniques. 3D finite element models were developed with consideration of realistic solder joint shape and the actual coating profile. Thermal mechanical simulations were carried out for three cycles under accelerated thermal test conditions of -25 to $100^{\circ} \mathrm{C}, 10$ minutes ramp and 10 minutes dwell. The inelastic strain energy density accumulated over one temperature cycle was used as an indicator for solder damage in the QFNs under the applied thermal cycling load. The impact of coating penetration level on the solder damage in QFNs was investigated for two types of coatings with different properties. The results show that coating penetrated underneath the package has significant impact on the solder joint damage in QFNs and the level of this impact depends on the coating properties and penetration level. When coating penetration level decreases, damage in the solder joint does not always decrease. In order to prevent coating penetration underneath the package, an edgebond adhesive was applied on the edge of the QFN assemblies prior to the application of the conformal coating. The modelling results show that using edgebond adhesive can reduce the solder joint damage in the investigated QFNs and thus improve their thermal fatigue reliability. When edgebond adhesive is used, the impact of conformal coating on the reliability of solder joints in QFNs is significantly reduced.
\end{abstract}

Keywords-QFNs; conformal coating; modeling; edgebond adhesive; reliability

\section{INTRODUCTION}

QFNs (Quad-Flat No Leads) are one of the most successful packages today in the consumer electronics market. Compared with other no-lead packages, they offer small form factor, good electrical and thermal performance, and are generally lower in cost [1,2]. The manufacturers of high reliability electronic systems, who rely on the commercial electronics supply chain for advanced packages, are considering and adopting QFNs in their systems in order to meet the requirements of cost, miniaturization and functionality [3].

When components and printed circuit board (PCBs) are intended for use in high reliability applications, conformal coatings are often considered to protect them from respective operational/harsh environments. When QFNs are conformally coated, the coating material can penetrate underneath the package and fill the gap between the package and the PCB (as shown in Figure 1. During thermal cycling, coating penetrated under the package expands and shrinks as temperature changes, and thus can influence the reliability of solder joints. A previous study [4] has investigated the impact of conformal coating on QFNs' reliability using six variants of QFN packages and two types of conformal coatings. The results from the work revealed that conformal coating played a complex role in the damaging mechanisms of QFN solder joints, and the level of the impact had strong dependence on the coating properties and package size. It was found that, in general, the presence of conformal coating plays a negative role in the solder joints' thermal fatigue reliability for QFN packages.

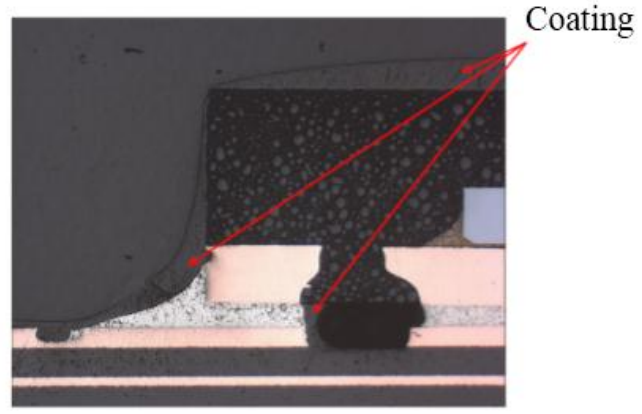

Figure 1. Conformal coating coated QFN

In this paper, further analysis using numerical simulations was carried out to investigate the impact of conformal coating penetration on the solder reliability in QFNs. A plastic QFN and two types of conformal coating (Coatings A and B) were investigated. Figure 2 shows the selected QFN component and provides details of the coating profile when coating material $\mathrm{A}$ is used. This QFN package has dimensions of $5 \mathrm{~mm} \times 5 \mathrm{~mm} \times$ $0.75 \mathrm{~mm}$, and there are eight solder joints at each side of the component when assembled onto a PCB.

Thermal mechanical simulations were carried out using a range of coating penetration levels. The impact of coating penetration on solder reliability in QFNs was evaluated for two coatings with different properties. A strategy to prevent coating penetration underneath the package by using an edgebond adhesive was also investigated. Reliability testing of these edge-sealed QFN packages is currently ongoing; testing results will be reported in future publications. 

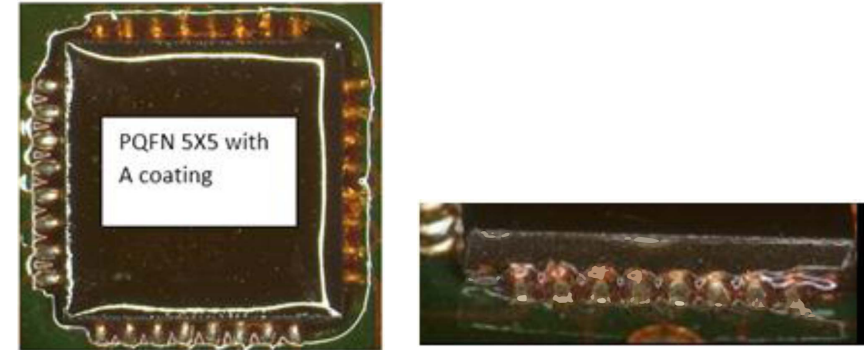

Figure 2. Conformal coating coated QFN (top and side views)

\section{MODELLING METHODOLOGY}

In order to generate detailed three-dimensional CAD models for the finite element analysis and complement the limited geometric data in the supplier's technical data sheets, detailed package and materials characterization was undertaken to obtain materials data and package construction data. This data was then used to undertake the thermo-mechanical modelling. The overall modelling workflow is detailed in Figure 3.

Models were developed with considerations of detailed pad design, realistic shape of solder joint and solder fillet. The thickness profile of the conformal coatings and the coating penetration level underneath the package were taken from experimentally measured data. The shape of the solder joint and solder fillet was defined using the experimental measured solder standard-off height and the manufacturer's target of the solder joint volume for each type of QFN assembly.

Commercial software ANSYS was used for all aspects of the modeling: pre-processing, solution and post-processing. Due to symmetry, only one-quarter of the package-board assembly was modeled. The 3D finite element model developed for the QFN assembly is shown in Figure 4.

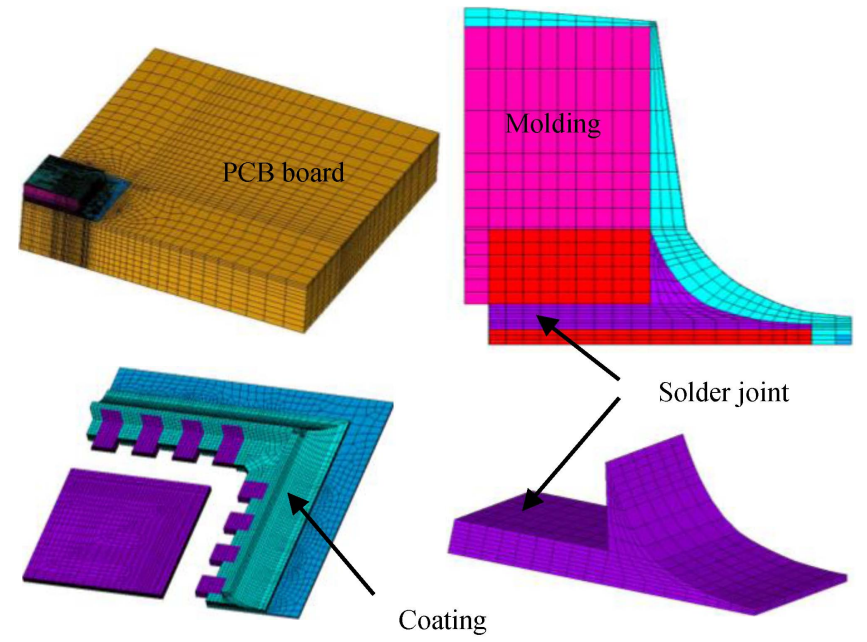

Figure 4. FE mesh model for QFN component assembly

All materials were assumed linear elastic, except solder where nonlinear material properties were used. Table 1 lists the temperature dependent material data measured for conformal coatings, and Table 2 summarizes the material data used for the rest of the materials. The Anand visco-plastic constitutive model was used to represent the deformation behaviour of the solder. In the Anand model, plasticity and creep are unified and described by the same set of flow and evolution relations; the details of these equations can be found in the literature [5], while the Anand constants for $\mathrm{Sn} 62 / \mathrm{Pb} 36 / \mathrm{Ag} 2$ solder that were used in this work were taken from the literature [6].

The thermal loading profile used in the simulations is shown in Figure 5. It matches the test conditions of the accelerated thermal cycling test: -25 to $100^{\circ} \mathrm{C}$, with 10 minutes ramp and 10 minutes dwell. The starting temperature was defined as the solder solidification temperature of Sn62/Pb36/Ag2 solder, to take into account the residual stress in the solder joint from the reflow process.

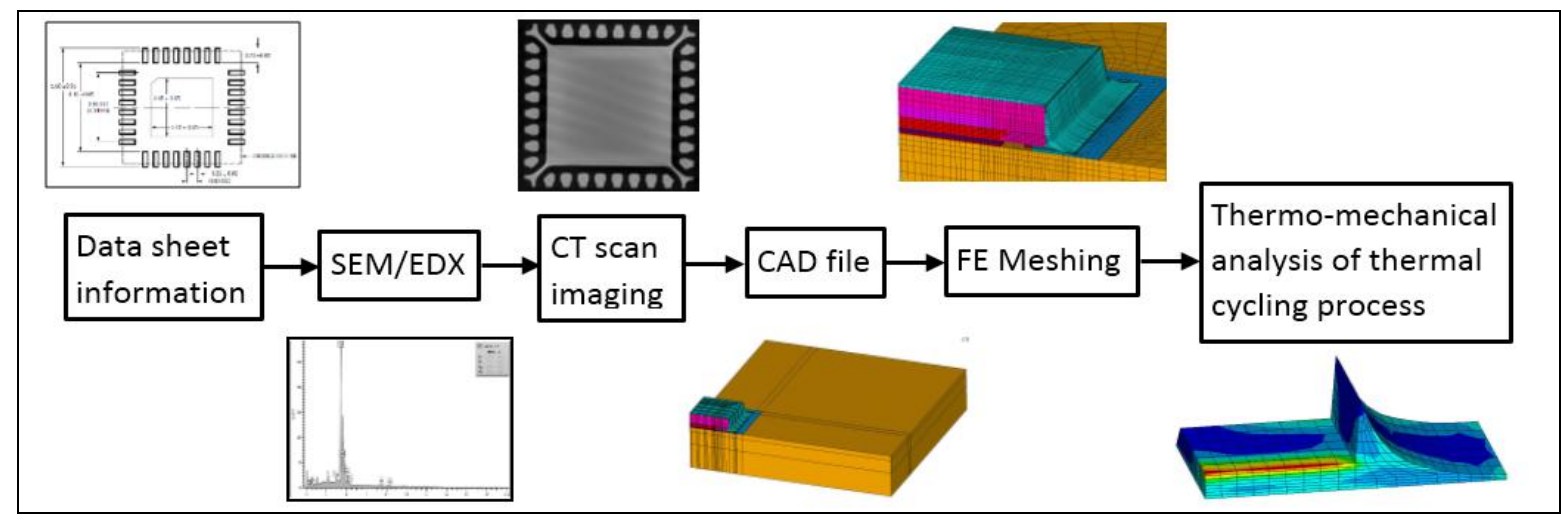

Figure 3. Modelling workflow 
Table 1. Material data of conformal coatings

\begin{tabular}{|c|c|c|c|}
\hline $\begin{array}{l}\text { Conformal } \\
\text { coating }\end{array}$ & $\begin{array}{l}\text { Young's Modulus } \\
\text { (MPa) }\end{array}$ & $\mathrm{CTE}\left(\mathrm{ppm} /{ }^{\circ} \mathrm{C}\right)$ & $\begin{array}{l}\mathbf{T}_{g} \\
\left({ }^{\circ} \mathbf{C}\right)\end{array}$ \\
\hline A coating & $\begin{array}{ll}3840 & \text { at }-55^{\circ} \mathrm{C} \\
3310 & \text { at }-20^{\circ} \mathrm{C} \\
3020 & \text { at }-0^{\circ} \mathrm{C} \\
2590 & \text { at } 20^{\circ} \mathrm{C} \\
1950 & \text { at } 40^{\circ} \mathrm{C} \\
820 & \text { at } 60^{\circ} \mathrm{C} \\
30 & \text { at } 80^{\circ} \mathrm{C} \\
6 & \text { at } 100^{\circ} \mathrm{C}\end{array}$ & $\begin{array}{l}193 \text { below } T_{g} \\
340 \text { above } T_{g}\end{array}$ & 26 \\
\hline B coating & $\begin{array}{ll}7950 & \text { at }-55^{\circ} \mathrm{C} \\
6490 & \text { at }-20^{\circ} \mathrm{C} \\
5370 & \text { at }-0^{\circ} \mathrm{C} \\
3690 & \text { at } 20^{\circ} \mathrm{C} \\
1180 & \text { at } 40^{\circ} \mathrm{C} \\
50 & \text { at } 60^{\circ} \mathrm{C} \\
7 & \text { at } 80^{\circ} \mathrm{C} \\
3 & \text { at } 93^{\circ} \mathrm{C}\end{array}$ & $\begin{array}{l}112.9 \text { below } T_{g} \\
300 \text { above } T_{g}\end{array}$ & 43.2 \\
\hline
\end{tabular}

Table 2. Material data for other materials in the assembly

\begin{tabular}{|l|l|l|l|l|}
\hline $\begin{array}{l}\text { Property } \\
\text { Material }\end{array}$ & Modulus (MPa) & $\begin{array}{l}\text { CTE } \\
\left(\mathbf{p p m} /{ }^{\circ} \mathbf{C}\right)\end{array}$ & $\begin{array}{l}\text { Poisson's } \\
\text { ratio }\end{array}$ & $\begin{array}{l}\mathbf{T}_{\mathrm{g}} \\
\left({ }^{\circ} \mathbf{C}\right)\end{array}$ \\
\hline Solder & $\begin{array}{l}40000 \text { at- } 50^{\circ} \mathrm{C} \\
21800 \text { at } 60^{\circ} \mathrm{C} \\
12800 \text { at } 100^{\circ} \mathrm{C}\end{array}$ & 26 & 0.4 & \\
\hline Copper & 120000 & 16.6 & 0.34 & \\
\hline & & & & \\
\hline $\begin{array}{l}\text { Solder } \\
\text { mask }\end{array}$ & 3800 & 70 & 0.4 & \\
\hline Moulding & $\begin{array}{l}29006 \text { at } 25^{\circ} \mathrm{C} \\
920 \text { at } 260^{\circ} \mathrm{C}\end{array}$ & $\begin{array}{l}7\left(<\mathrm{T}_{\mathrm{g}}\right) \\
34\left(>\mathrm{T}_{\mathrm{g}}\right)\end{array}$ & 0.4 & 135 \\
\hline Die attach & $\begin{array}{l}9356 \text { at }-65^{\circ} \mathrm{C} \\
7840 \text { at } 25^{\circ} \mathrm{C} \\
6337 \text { at } 100^{\circ} \mathrm{C} \\
5092 \text { at } 150^{\circ} \mathrm{C}\end{array}$ & $\begin{array}{l}61\left(<\mathrm{T}_{\mathrm{g}}\right) \\
\text { at } 200^{\circ} \mathrm{C}\end{array}$ & 0.4 & 241 \\
\hline $\begin{array}{l}\text { PCB } \\
\text { board }\end{array}$ & 22000 & $\begin{array}{l}16(\mathrm{x}-\mathrm{y}) \\
39(\mathrm{z})\end{array}$ & 0.35 & 159 \\
\hline Silicon & 163000 & 2.69 & 0.28 & \\
\hline
\end{tabular}

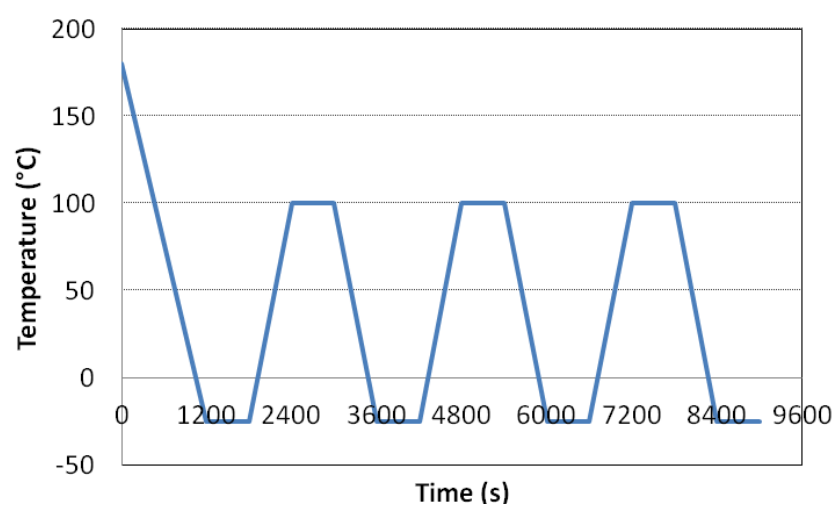

Figure 5. Loading profile used for simulations

The inelastic strain energy density was used as an indicator of the damage induced in the second-level solder interconnects under the applied thermal cycling load. Figure 6 shows the damage distribution in the solder joints in a conformal coating coated QFN assembly at $-25^{\circ} \mathrm{C}$ (the end of the third temperature cycle at which the damage metric has stabilized). It is shown that the critical solder joint is located at the package corner which has the largest distance to the neutral point (DNP). During the thermal cycling test, the crack is likely to occur along the interface between component pad and the solder, and propagates into the solder fillet as illustrated by the arrow in Figure 6. The volume-averaged damage accumulated over the third temperature cycle in the solder joint was calculated for the corner solder joint using the top three layers elements $(\sim 25 \mu \mathrm{m}$ in thickness) under the component pad and some elements in the solder fillet.

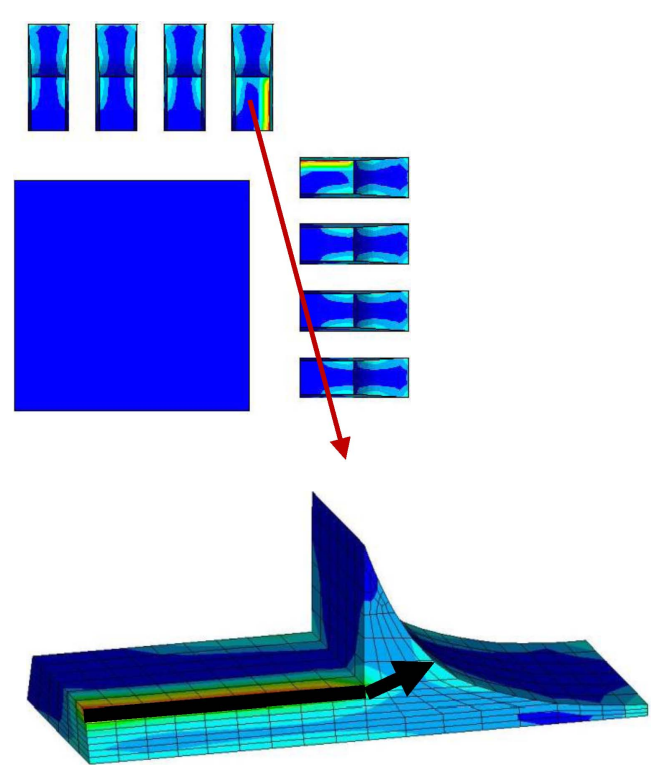

Figure 6. Damage distribution in solder joints

\section{MODELLING RESULTS}

Using the developed finite element models, thermal mechanical simulations were carried out to investigate the impact of coating penetration level and of edgebond adhesive on the solder reliability in QFNs. In each case, the damage (inelastic strain energy density) in the corner solder joint was calculated.

\section{A. Impact of coating penetration level}

The impact of coating penetration level on solder reliability in QFNs was investigated using two types of conformal coatings (Coating $\mathrm{A}$ and Coating B). These two coatings have very different material properties, for example, Coating A has a much higher CTE than Coating B. The coating penetration level (L) is defined as the distance between the coating penetration stop line and the edge of the package, as illustrated in Figure 7. In the simulations, when the coating penetration level increases from 0 to $525 \mu \mathrm{m}$, the coating profile on the top and side surface of the assembly remains unchanged.

Figure 8 (a) and (b) shows the simulation results when coatings A and B are used respectively. When Coating B is 
used, the predicted damage decreases when the coating penetration level decreases. However, when Coating A is used, the predicted solder damage decreases first and then increases when the coating penetration level increases from 0 to $525 \mu \mathrm{m}$. These results indicate that the impact of coating penetration on the solder reliability in QFNs has strong dependence on the coating properties. Reducing the coating penetration underneath the package may not result in a decrease in solder damage and improvement in QFN reliability.

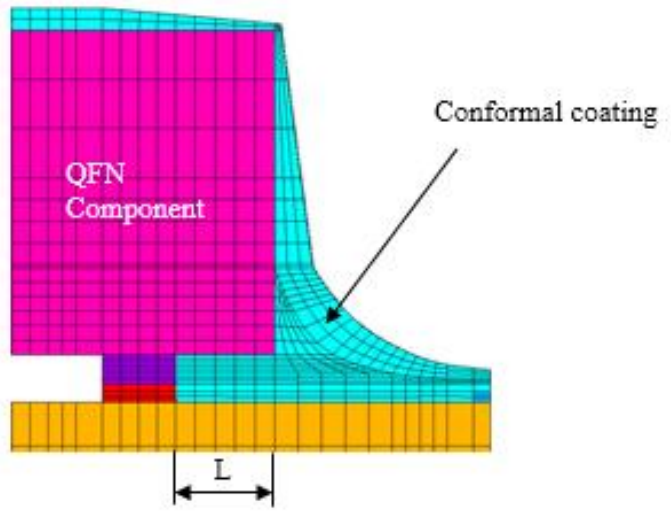

Figure 7. Definition of the coating penetration level

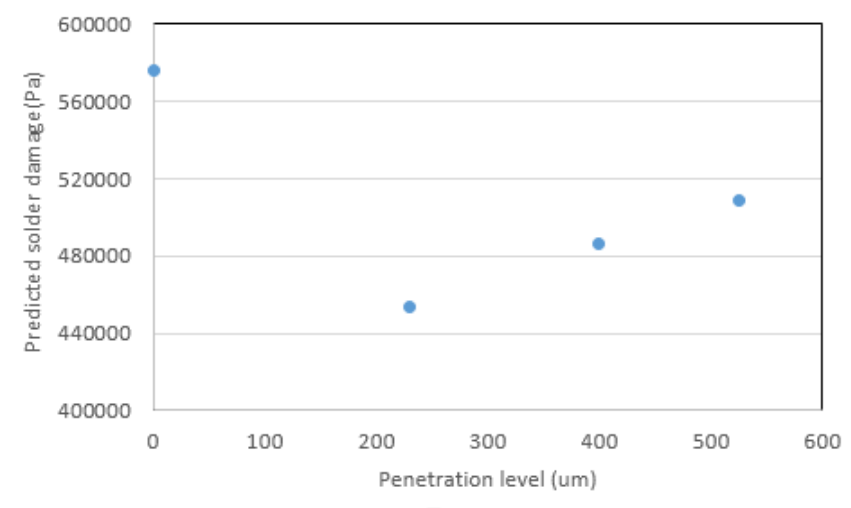

(a) When A coating is used

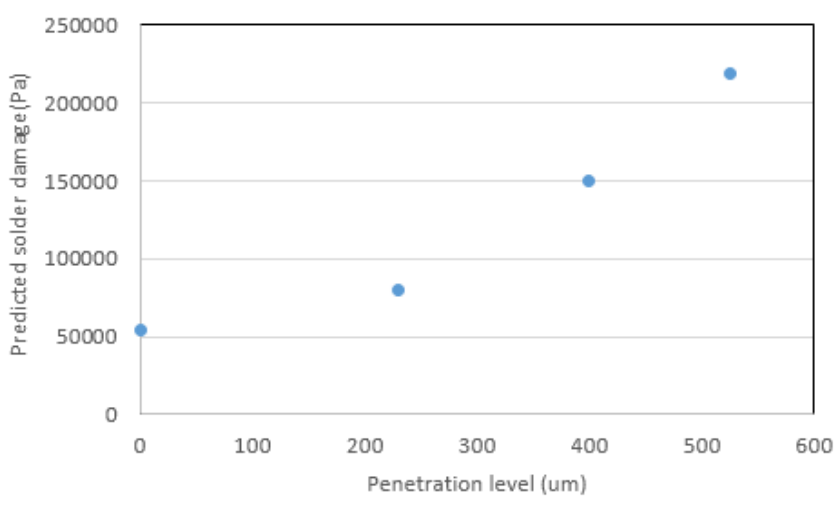

(b) When B coating is used

Figure 8 . Solder damage with variant coating penetration levels

\section{B. Impact of using edgebond adhesive}

In order to prevent the conformal coating penetration underneath the package, an edgebond adhesive can be applied on the edge of the QFNs prior to the application of the conformal coating. Previous studies [7, 8] has revealed that using edgebond adhesive can improve thermal cycling reliability of BGA type area-array packages if the chosen adhesive has a lower CTE which matches the CTE of the solder material. The material properties of the edgebond adhesive tested in this work are shown in Table 3.

Table 3. Material data of edgebond adhesive

\begin{tabular}{|l|l|l|l|}
\hline & $\begin{array}{l}\text { Young's } \\
\text { Modulus (MPa) }\end{array}$ & $\mathbf{C T E}\left(\mathbf{p p m} /{ }^{\circ} \mathbf{C}\right)$ & $\mathbf{T} \mathbf{g}\left({ }^{\circ} \mathbf{C}\right)$ \\
\hline $\begin{array}{l}\text { Edgebond } \\
\text { adhesive }\end{array}$ & 7300 & 25.0 at $-20^{\circ} \mathrm{C}$ & 103 \\
& & 28.6 at $0^{\circ} \mathrm{C}$ & \\
& & 29.7 at $20^{\circ} \mathrm{C}$ & \\
& & 35.9 at $40^{\circ} \mathrm{C}$ & \\
& & 43.9 at $60^{\circ} \mathrm{C}$ & \\
& & 50.8 at $80^{\circ} \mathrm{C}$ & \\
& & 47.3 at $100^{\circ} \mathrm{C}$ & \\
\hline
\end{tabular}

A cross-section image of the QFN assembly with the edgebond adhesive is shown in Figure 9. As with the conformal coatings, some amount of the edgebond adhesive will penetrate underneath the package. The level of the penetration was measured experimentally as $430 \mu \mathrm{m}$ from the edge of the package.

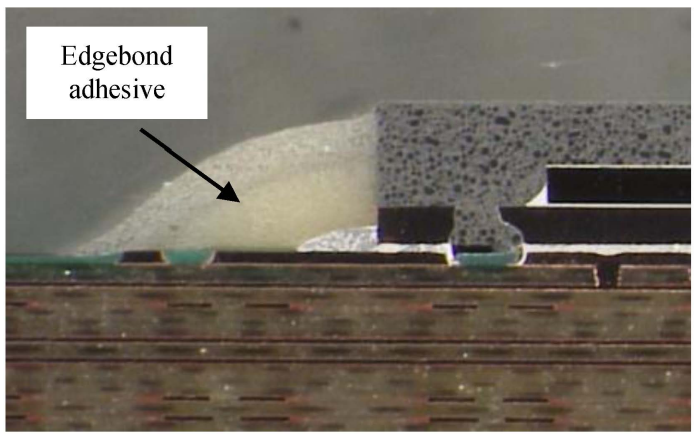

Figure 9. Cross section image of the QFN assembly using edgebond adhesive

Using the experimentally measured geometry profile of the edgebond adhesive, the baseline model of the QFN assembly was updated to include the edgebond adhesive and conformal coating, as shown in Figure 10. When edgebond adhesive is used, there is no direct contact between the conformal coating and the solder joint. The conformal coating investigated in this work is Coating A.

Thermal mechanical simulations were carried out using the models developed, and Figure 11 shows the damage distribution in the solder joints for each case. It is shown that the critical solder joint is always located in the corner of the package, and using edgebond adhesive has helped reduce the solder damage in the QFN. Within the corner solder joint, using edgebond adhesive has changed the damage distribution. The location of higher damage has changed from the interface between the solder joint and the package pad to the interface 
between the solder joint and the PCB pad. However, the presence of the conformal coating shows little impact on the magnitude and distribution of the solder damage.

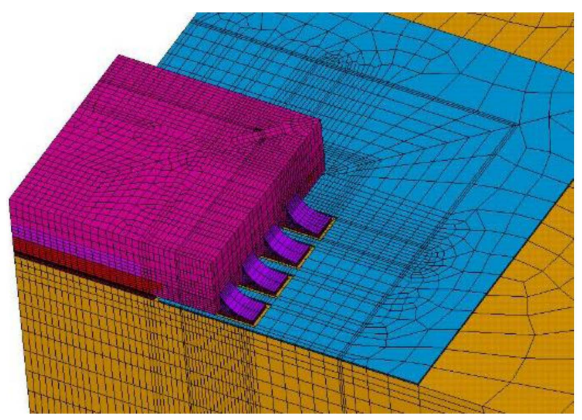

(a) Baseline model

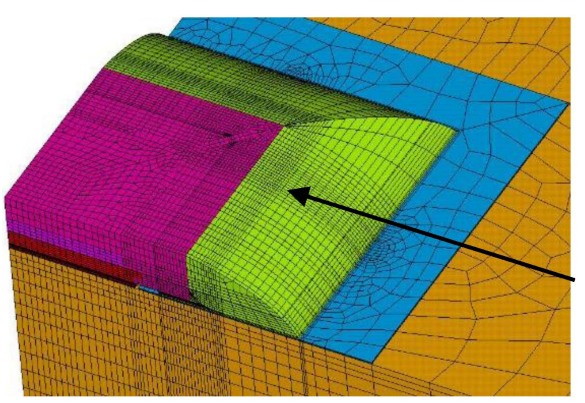

Edgebond adhesive

(b) Baseline model with edgebond adhesive

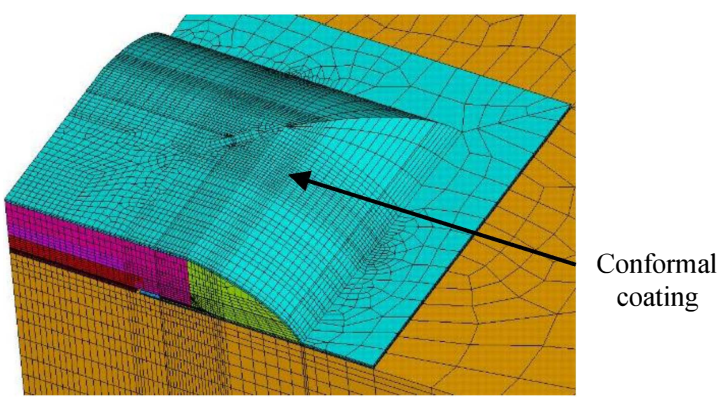

(c) Baseline model with edgebond adhesive and conformal coating

Figure 10. Mesh models for QFN with and without edgebond adhesive

The volume averaged solder damage accumulated over the third temperature cycle was calculated and the results are shown in Figure 12. Three layers of elements along the interface between the solder joint and PCB pad were chosen for the cases where edgebond adhesive was used. The results show that using edgebond adhesive can reduce the solder damage significantly (from $\sim 0.2 \mathrm{MPa}$ to $\sim 0.06 \mathrm{MPa}$ ). Although using conformal coating increases the solder damage, the overall impact of using edgebond adhesive and conformal coating is beneficial and has reduced the solder damage in the QFN assembly by $65 \%$.

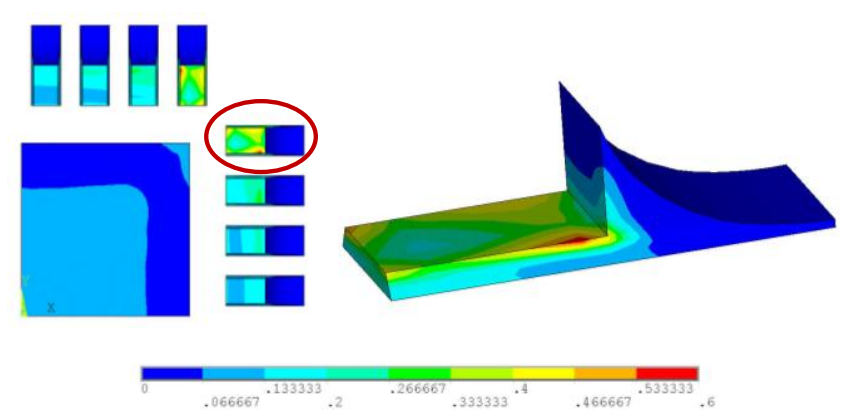

(a) Baseline model

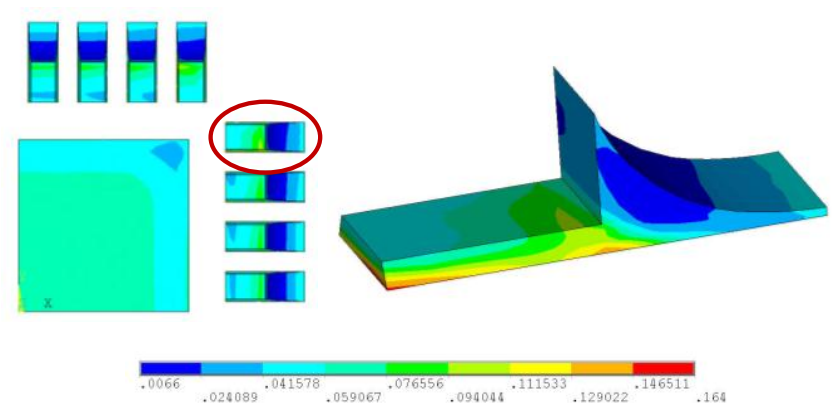

(b) With edgebond adhesive

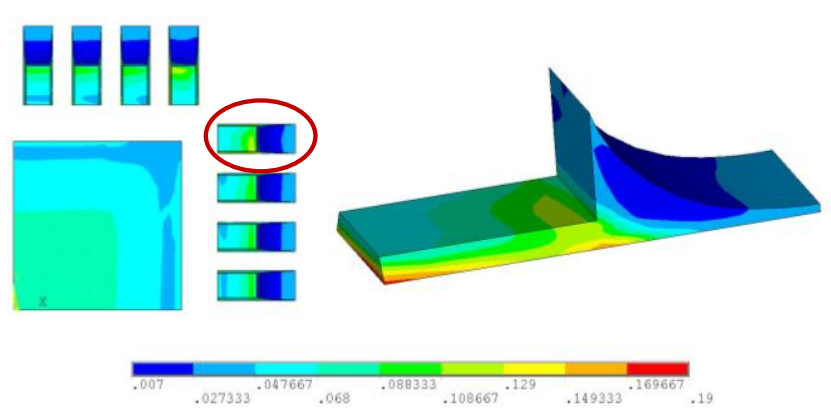

(c) With edgebond adhesive and conformal coating

Figure 11. Distribution of damage accumulated over the third temperature cycle (unit: MPa)

\section{CONCLUSION}

In this paper, the impact of conformal coating penetration on QFN reliability was investigated using finite element analysis. 3D finite element models were developed and thermal mechanical simulations for solder damage evaluation were carried out. The outcome was as follows. 


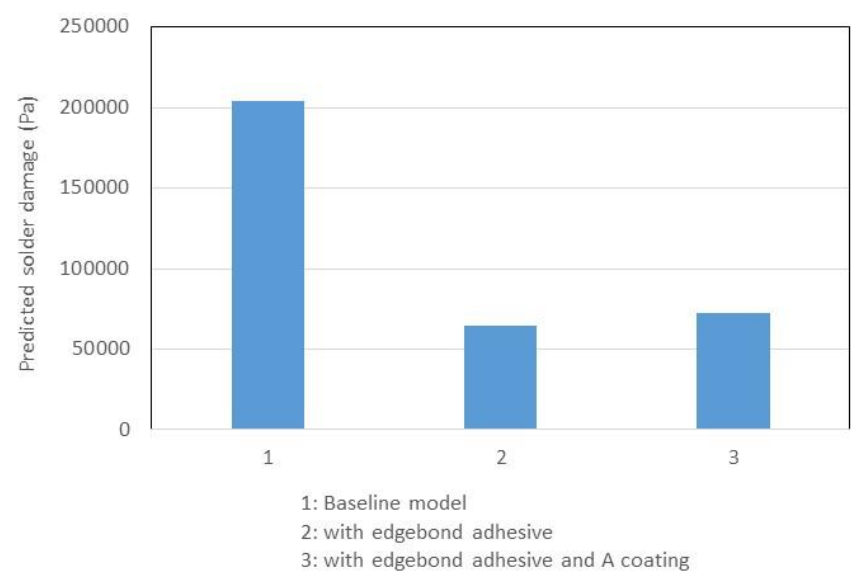

Figure 12. Predicted volume-averaged solder damage

1) Coating penetrated underneath the package has significant impact on the solder joint reliability in QFNs. The level of this impact depends on the coating properties and penetration level. When conformal Coating A is used, solder damage reduces initially but then increases when the coating penetration level increases from 0 to $525 \mu \mathrm{m}$. When Coating B is used, solder damage increases with the coating penetration level. This result indicates that reducing the coating penetration level underneath a QFN package may not always reduce the solder damage, because conformal coating plays a complex role in solder joint reliability.

2) When edgebond adhesive is applied prior to the application of the conformal coating, it prevents the coating from penetrating underneath the QFN package. Therefore, the impact of the conformal coating on the QFNs' solder joint reliability is reduced. It was also found that using edgebond adhesive can improve the solder reliability in QFNs. Using edgebond adhesive with conformal coating together, solder damage in the QFN is reduced by 65\% compared with the baseline model.

As part of the future work, the impact of edgebond adhesive on QFN reliability will be studied experimentally using accelerated thermal cycling test. The experimental results will be used to validate the findings reported in this paper. Early test results indicate that edgebond adhesive has beneficial impact when compared with earlier coated experimental results.

\section{ACKNOWLEDGMENT}

The authors would like to acknowledge the support from Leonard MW Ltd in terms of access to test and materials data, and Prof. John Roulston from Scimus Solutions Ltd for valuable inputs to the project.

\section{REFERENCES}

[1] Ahmer Syed and WonJoon Kang, "Board Level Assembly and Reliability Considerations for QFN Type Packages", 2003 SMTA conference, USA.

[2] Guofeng Xia, Fei Qin, Wenhui Zhu et al. "Comparative Analysis of Reliability Between Dual-row and Conventional QFN Packages", Proceedings of 2012 Int. Conf. on Electronic Packaging Technology \& High Density Packaging, page 616-619.

[3] Paul Vianco, Michael K Neilsen, "Thermal Mechanical Fatigue of a 56 I/O Plastic Quad-Flat Nolead (PQFN) Packaging", Proceedings of SMTA International Conference, Rosemont, page 85-94, 2015.

[4] Yin, C, Stoyanov, S, Bailey, C, Stewart, P, and McCallum, S "Reliability Assessment of QFN Components for Aerospace Applications", Proceedings of IEEE 66th Electronic Components and Technology Conference, 31 May-3 June 2016, Las Vegas, Nevada, USA, pp. 1996-2002 (DOI 10.1109/ECTC.2016.186)

[5] Li Li, "Reliability Modelling and Testing of Advanced QFN Packages", Proceedings of 2013 ECTC conference, page 725-730.

[6] Stephan Stoeckl and Heinz Pape, "Improving the Solder Joint Reliability of VQFN Packages", Proceedings of 2005 Electronics Packaging Technology Conference, page 760-767

[7] Hongbin Shi, F.X.Che, et al. "Analysis of edge and corner bonded PSvfBGA reliability under thermal cycling conditions by experimental and finite element methods", Microelectronics Reliability, V52, page $1870-1875,2012$

[8] Simon Chang, Kar I. Loh and Edward S. Ibe, "Underfill and Edgebond for Enhancing of Board Level Reliability", proceedings of 2014 International Microsystems, Packaging, Assembly and Circuits Technology Conference, page 65-68. 